\title{
Participation in a Diabetes Education and Care Program: Experience from the Diabetes Care for Older Adults Project
}

\author{
MARTHA MITCHELL FUNNELL, MS. RN. CDE: MARILYNN S. ARNOLD, MS, RD. CDE: \\ JANET FOGLER, MSW; JENNIFER H. MERRITT. MSN. RN. CDE: LYNDA A. ANDERSON. PhD
}

There is very little reported information concerning the participation of older adults in diabetes education and care programs, factors retated to their attendance, and the influence of attendance on program outcomes. In this studs: which was part of a larger study of insulin therap?: subjects ( $\geq 65$ years old) assigned to the intensive management group (n=53) were provided with educational sessions during the 18-month study period. Data for this group were examined to determine factors that influenced enrollment and attendance. Attendance rates for individual participants averaged $72 \%$ during the first 6 months and $68 \%$ during the subsequent 12 months. Demographic factors, baseline knowledge test scores, and baseline glycosylated hemoglobin levels did not significantly influence participation. Greater distance from the clinic and shorter time using insulin were significantly related $(P=.05)$ to attendance. Perceived benefits of the program included diabetes education (45\%), glucose control (23\%), and interacting with others who have diabetes $(23 \%)$.
Diabetes is extremely common among older alults" and represents a significant health risk for this population." It is estimated that over 3 million adults age 65 years and older have diabetes.' In spite of this high prevalence. older adults with diabetes receive less diabetes self-maniagement educittion than their younger counterparts." For cxample. in a large study of 2268 adults with type 2 diabetes mellitus. younger age was one of the variables associated with attendance at a diabetes education program. Among participants 6.5 years or older in that sample. only $41 \%$ of those trealed with insulin and $21 \%$ of those not on insulin had attended at diabetes education class or program. In contrast. 59\% and $35 \%$, respectively, of participants between ages 18 and 39 years, and $54 \%$ and $25 \%$, respectively, of participants between ages 40 and 64 years' had attended a diabetes education class or program.

Educational programs developed specifically for older adults have been shown to be effective in helping them lose weight ${ }^{\mathrm{x} .0}$ as well als improve cating and exercise hehavior patterns." metabolic control." and psychosocial functioning." "Unfortunately, few educational programs assess education and treatment interventions designed to meet the particular needs of this age group." The reasons for this lack of assessment are largely unknown. but may reflect the beliefs that older adults are unable to participate in educational programs or require an excessive amount of education and support to carry out more intensive regimens. Because the factors that may influence older adults" participation in and response to interventions halve not been reported, very little is known about the types of education and carc programs that are most appealing. feasible. and effective for this age group. Although there has been some work on the representativeness of samples selected for study." there is al dearth of information on whether program outcomes are influenced by the

From the Diabetes Research and Training Center (Mss Funnell and Arnold), the Turner Outpatient Geriatric Clinic (Mss Fogler and Merritt), The University of Michigan, Ann Arbor, Michigan: and the Centers for Disease Control and Prevention. Atlanta. Georgia (Dr Anderson).

This study was supported in part by a grant from the National Institute of Diabetes, Digestive and Kidney Diseases of the National Institutes of Health, Grant No. NIH5P60DK20572-19.

Correspondence to Marthil Funnell, MDRTC, C333 Med-Inn, Box 0832. University Hospitals. 1500 East Medical Center Drive, Ann Arbor MI 48109-0832. E-mail: MFunnell(wumich.cdu

Reprint requests to The Diabetes Educator: 367 West Chicago Avenue, Chicago IL 60610-3025. 
level of participation (or attendance) in the education and support programs.

We took the opportunity to examine the important issue of attendance while conducting the Diabetes Care for Older Adults Project (DCOAP), a successful intensive management project for older adults." The purposes of this article are to (1) document attendance of participants in the DCOAP education and support programs. (2) examine potential factors related to attendance. and (3) explore reasons participants joined the DCOAP study.

The Diabetes Care for Older Adults Project provided a comprehensive team care and education program for older adults in which insulin therapy was the primary intervention. The goal of this project was for experimental subjects 10 achieve a glycated hemoglobin value of less than $9 \%$. with the ultimate goal of preventing the long-term complications of diabetes." This more ageressive approach to care can be contrasted with basic diabeles care in older adults in which the goal is only to prevent symptomatic hyperglycemia." Although intensive insulin therapy is controversial among this population. until the risk-fo-benefit ratio is known. older adults deserve the same consideration and the same right 10 choose more aggressive treatment programs and optimal blood glucose goals as younger adults.

\section{Research Design and Methods}

The DCOAP was a 3-year randomized clinical trial designed to compare the benefits and risks of an intensive team care program with conventional therapy for older addults with diabetes." Team care group subjects participated in a program of intensive insulin management provided by a diabetes care team and a series of education and support group sessions. Most participants $(80 \%$ ) were recruited from newspaper advertisements in the Detroit metropolitan area." Inclusion criteria were age greater than 64 years. diagnosis of diabetes for at least 6 months. stable general health. and glycated hemoglobin greater than $9 \%$ (normal=4\% to $8 \%$ ). Almost all participants had type 2 diabetes. Participants randomized to the team care (intensive) group had a targeted glycaled hemoglobin level of less than $9 \%$. were prescribed insulin. were anked to monitor their blood glucose at home at least twice a day, and were offered a diabetes education and social support program. Participants randomized to the conventional therapy (control) group were followed by their physician of choice and continued on conventional mamagement. They were seen every 6 months for data collection. There were no significant differences between the iwo groups in terms of demographic characteristics. baseline glycosylated hemoglobin levels, or insulin use. Prior to randomization, informed consent was obtained for study participation as established by the Institutional Review Board of the University of Michigan Medical Center. Significant differences were found between the glycosylated hemoglobin levels of the two groups at 6. 12. and 18 months and have been reported elsewhere."

Subjects A total of 103 persons with diabetes age 65 years and over participated in the DCOAP. Of these. 53 were randomized to the team care group and consequently offered the diabetes education and support group program. Demographic characteristics of the team care group are presented

Table 1. Demographic Data for the Team Care Group, $n=53$

\section{Characteristic}

Age. $y$

\begin{tabular}{|c|c|}
\hline Mcan (SD) & $69.5(+.3)$ \\
\hline Female. \% & 54.7 \\
\hline Ciuculsian. \% & 94.3 \\
\hline$>$ High xhool cducation. \% & 66.0 \\
\hline Marricd $C_{t}$ & 52.8 \\
\hline \multicolumn{2}{|l|}{ Duration of diabetes, $y$} \\
\hline Mein (SD) & $15.0(1)$ \\
\hline Presioun formal dialhetes education. \% & 71.2 \\
\hline
\end{tabular}

in Table 1. Forly-one $177 \%$ ) were on insulin therapy upon entry into the study. with a mean duration of insulin use of 12 years $(S D=12.15$, range $=6$ mo to $52 \mathrm{y}$ ). At balseline, the team care participants had a mean glycated hemoglobin level of 12.5\% (SD=2.4). Seventy-eight percent rated their health as good to fair.

Education and Support Program The education and support required by older adults to achieve optimal glucose control is largely unknown. However. it is recommended that a team approach be used and that the patients and their support systems become integral components of the healthcare team." The education and support component of the DCOAP was designed to foster this interaction.

An interdisciplinary tcam consisting of a clinical nurse specialist, registered dictitian. and social worker led the sessions for intensive group subjects. Both the nurses and the dietitian were Certified Diabetes Educators (CDEs). The 12-session program was offered only to participants in the team care group and was designed to support the goals of the project rather than to provide general diabetes education. Thus, the program emphasized intensified insulin therapy to lower glycated hemoglobin values and assisted participants in salfely dealing with the challenges of an intensive management program. Sessions were facilitated by various members of the healthcare team, discussion of psychosocial issues was incorporated into the educational program. and adequate time was allotted for patient/staff interaction. The program was specifically designed for older adults and was adapted from Non-Insulin-Dependent Diabetes Mellitus: $A$ Carriculum for Patients and Health Professionals. ". Topics for the education and support group sessions are listed in Table ?.

Teaching strategies appropriate for older adults were used to develop and implement the sessions. Topics were selected hased on their applicibility to intensive therapy and to assist patients in successfully coping with the increased demands of this regimen. The sessions generally began with a review of previous content and an opportunity for participants to ask questions or raise problems. Each session focused on a particular content areal. and the pace allowed time for participants to assimilate the information. The use of lecture was minimal. while group discussion and responding to questions and concerns were promoted by limiting the number of instructor-generated obiectives per session. This approach 


\section{Table 2. Topics for Educational/Support Sessions}

Introduction and individual teaching

Overview of project: imsulin injection. hlond glucose monitoring. and hypoglycemia

O)erview of diabetes

Definition of diabetes and its tratment; safe use of insulin therapy

Fond and blood sugar

Impact of various foods on bluxd glucose (designed to assist palticipants in using monitoring information and making informed choices)

Feelings about diabetes

Concerns and isstes common lo older adults with diabeter

Intensive insulin therapy

Why and how ol incensive therapy

Weight, fats, and labels

Strategies to limit weight gatin. recognize the impalct of fats, and learn label reading for informed choice

Stress and coping

Impact of stress on blood glucose. stressors relalted 6 insulin therapy. and eoping strategies

Exercise and review of goals

Relationship/accommodation of exercise to hlood glucone and insulin therapy: review of project and persomal goals

Eating out

Food choices and insulin modifications when calling awaly from home

Resources and family support

Community resources and secking suppont lor intensive diabetes care

Risk factors and long-term complications

Overview of long-term complication (emphasising prevention. carly detection, and atandards of care)

Problem solving

Strategies to deal with isues (both physological and psychosocial) related to insulin therapy and personal goal attainment

allowed adequate time to address both instructor and participant-generated content. concerns, and issues.

Print materials were designed specifically for persons with type 2 diabetes and written at a sixth- to eighth-grade reading level. Videotapes featured older adults from various ethnic groups. Participants with diminished hearing and vision were seated next to the instructor during the class sessions. No participants had severe sensory deficits. Becaluse of the value of peer support for diabeles education and control, ${ }^{\text {mlls }}$ patient-to-patient interiction wals also promoted. This interaction was accomplished through the use of a slaged enrollment process whereby all patients in a group participalted together throughout the project.

Study participants met regularly during the 18 -month intervention period. Instructions related to insulin administrattion and blood glucose monitoring technique were given individually at the start of the project. Classes were held weekly for the first 3 consecutive weeks and focused on insulin use and managing hypoglycemia, blood glucose monitoring. and balancing diet and insulin. The next six group meetings were scheduled monthly, and the final three group sessions were held every other month. Class sessions lasted for $1 \frac{1 / 2}{2}$ hours and were held in the late morning or early afternoon. Visits with an advanced nurse practitioner. who also was a CDE. were scheduled around these group meetings as needed for insulin adjustment and individual instruction. During the data collection visits, which occurred at 6-month intervals, group meetings were not held. Clinic visits and blood glucose monitoring supplies, in most cases, were billed to Medicare or other insurers. Insulin was provided and there was no additional fee associated with the education and support program. Participants received no monetary in- centives for participating in the DCOAP and were responsible for their own transportation.

Eight to 13 subjects participated in each education and support scries, and significant others were encouraged to attend with them. The series was repeated six times over the 3 years of the project and generally remained consistent in content. The only notable change was an expanded session on exercise to incorporate a review of project and personal goals, and strategies for achieving these goals. All sessions were deliberutely kept informal with time allotted for questions, discussion, and interaction. Whenever possible, sessions began with armchair exercises, and each session included interactive learning activities. For example, participants assessed personal cost-benefits of improved glucose control. practiced reading food labels, and worked together to generalte potential solutions to issues common to people with diabetes. No individual meal planning was provided, although participants with special needs were referred to the dietitian if requested.

Data Collection A record-keeping log for each participant was initiated and maintained by the recruitment coordinator. Participants" records for each of the diabetes education and support sessions included attendance and reasons for not attending each session. To examine factors related to attendance, datia on basic demographic characteristics, treatment intervention, and participants' perceptions of diabetes were collected through baseline questionnaires. Knowledge was evaluated at baseline and at 6, 12. and 18 months using the Diabetes Knowledge Test (DKT)." a test of general diabetes knowledge designed for persons with type 2 diabetes taking insulin." Glycated hemoglobin levels were obtained through 
the laboratory services of the University of Michigan Diabetes Rescarch and Training Center. At the end of the study. participants were asked about their reasons for joining and the advantages and disadvantages of participation in the DCOAP.

\section{Results}

Attendance at Group Sessions Altendance at the education and support group sessions remained fairly high and stable over the 18 -month course of the project, with $72 \%$ attendance during the first 6 months and $68 \%$ attendance for the list 12 months of the study. Individual allendance ranged from 2 to 12 sessions (mean=7.9). No sessions had consistently more or fewer attendees than others. The primary reasons ciled by participants for missing sessions were being out of town. transportation problems, illness or hospitalization, and demands or crises of fimmily or friends.

The high attendance rate for the duration of the project may reflect recruitment methods and is consistent with lindings" that patients who are self-referred are more likely to join diabetes education programs. In addition. participants were screened before enrollment for their suitability and ability to carry out the regimen. and provided with a thorough explanation of the project goals and expectations. Given the focus on insulin use. it is not surprising that palients who had been using insulin for a shorter time were more likely to attend. These participants may have felt a greater need for information and support. It is surprising, however. that those who traveled greater distances were more likely to attend, which may hate reflected their level of overall health. a higher level of initial commitment, motivation for the program. or all of these reasons.

To further explore factors related to attendance, baseline variables that might intluence participation were examined. No demographic factors correlated w ith program attendance. The impact of knowledge scores and glycated hemoglobin levels also was evaluated. Average DKT scores were $70 \%$ correct $(S D=4.7)$. and average scores on the subset of diet questions were $57.4 \%$ correct $(S D=17.2)$. DKT scores increased significantly at the end of 6 months $(P=.033: 75 \%$ : $\pm 3.9)$ and were sustained at 12 and 18 months. Glycated hemoglobin levels were significantly lower at $6(9.9 \%)$ and 12 (9.1\%) months and were sustained at 18 months $(9.2 \%) . "$ However, neither of these measures was significantly correlated with attendance.

Previous insulin use and distance traveled to class correlated with two variables and were found to significantly influence attendance at the start of the study. Use of insulin for a shorter time among participants taking insulin was significantly correlated with attendance rates $(1=.52 . P<.03)$. Distance traveled also was signilicantly comelated with attendance: those who traveled farther $(>31$ miles) were more likely to attend $(r=.30, P<.03$ ).

The main reasons for joining the project were the desire for blood glucose control and diabetes education (Table 3). The opportunity for diabetes education was cited by almost half of the participants as the primary benefit they received from the program. Most respondents (24 of 53.62\%) said that there were no disadvantages to participation (Table 4).
Table 3. Reasons for Joining, $n=39$

\section{Characteristic}

n (\%)

Desire to control/help diabetes

$20(51)$

Diabetes education

$16(41)$

Scientilic reseatrch

Help finding a new plyysician

$3(5)$

Family/friend/MD encouraged joining

$2(8)$

Table 4. Advantages and Disadvantages of Participation, n=39

\section{Advantages}

n (\%)

Diabetes education

Better blood glucose control

Contact with other participants

$7(18)$

Contact with project personnel

$6(15)$

Introduction to monitoring

$5(12)$

\section{Disadvantages}

None

$24(62)$

Distance/transportation

$8(21)$

No weight loss

$2(5)$

Costhilling

$2(5)$

Only $10 \%$ said they would not participate in future diabetes programs or projects.

\section{Discussion}

Initial Diabetes Knowledge Test scores compared favorably with the DKT scores of a sample of 149 insulin-requiring subjects in a community study in Michigan using the DKT $(n=7.3 . x=66 \%)$. While knowledge test scores were significantly improved at the 6-month data collection point. the improvement was somewhat modest. This modest improvement may reflect, in part. the use of a general diabetes knowledge test rather than one more specific to the intensive insulin approach and curriculum of the DCOAP, or the need for additional education. The initial improvement is generally expected bccause more general diabetes content was provided at the start of the program. Improvement in knowledge test scores was sustained by ongoing participation. but scores did not continue to improve at 12 and 18 months.

Seventy-one percent of the participants had received formal diabetes education in the past. This percentage is greater than the $64 \%$ of insulin-requiring type 2 patients age 64 years and older in Michigan communities and the $41 \%$ reported by Coonrod.

Despite previous diabetes education and the availability of community resources, participants demonstrated less than ideal knowledge and blood glucose levels. The participants were generally very well educated, a reflection of the urban and university communities in southeastern Michigan where they lived. Most had had diabetes for some time and were taking insulin. Although three major medical centers are available to this population, most of whom have Medicare 
coverage for diabetes care and education, baseline DKT scores and glycated hemoglobin levels did not reflect optimal diabetes carc and education.

The datia demonstrate that the number of sessions attended did not independently influence DKT scores and glycated hemoglobin levels. Differences in outcomes between the two groups would indicate that the results are related to the project. However, it is not possible to determine the impact of the education and support sessions on outcomes separate from treatment because all participants in the team care group received all aspects of the intervention. The primary reasons participants stated they joined and the major advantages of the DCOAP cited at the end of the study were blood glucose control and diabetes education. The fact that reasons for joining and major advantages cited at the end of the study were consistent is an indication that participants perceived that the project met its goals. Many patients indicated anecdotally that one of their reasons for joining was that they took diabetes far more seriously than their physicians and saw the program as a way to receive help for their diabetes care. Their interest in blood glucose control and education at the start of the project may reflect their previous experience with diabetes education and/or their understanding of the need to be active participants in their own care. The fact that the majority of patients identified education as the primary advantage. stated no disadvantages, and expressed an interest in participating in future projects suggests both the value and need for developing programs and projects specifically for older adults.

Interpretation of the results of this study is limited by the sample. which may or may not be reflective of most older adults with diabetes. This particular group of older adults was well educated, independent. and had transportation available. Another limitation is lack of a true control group for just the educational aspects of the program so that the independent effect of the education on outcomes could be determined.

The results of this study do, however, demonstrate that older adults are able to actively participate in and benefit from a combined care and education program that supports optimal diabetes management. Additional programs designed specifically for this population. for whom diabetes represents a significant health risk, that focus on other aspects of diabetes care need to be developed and tested. In addition. more work is needed to determine the effects of the various components of these programs on outcomes.

\section{References}

\section{Barrett-Connor E. Commentary. Diabetes Spectrum 1989:2:16+-66.}

2. Harris MJ. Epidemiology of diabetes mellitus among the elderly in the United States. Clin Geriatr Med 1990:6:703-19.
3. Harris MI. Undiagnosed NIDDM: clinical and public heilth issues. Diabetes Care 1993:16:642-52

4. Kenny SJ. Aupert RE. Geiss LS. Prevalence and incidence of noninsulin-dependent diabetes. In: Harris MI, ed. Diabeles in America. Ind ed. Bethesda, Md: National Institutes of Health, 1995:47-68.

5. Hiss RG, ed. Diabetes in communities II. Ann Arbor, Mich: University of Michigan. Diabetes Research and Training Center, 1992.

6. Jenny JL. A comparison of four age groups' adaptation to diabetes. Can J Public Health 1984:75:237-44.

7. Coonrod BA, Betschart J. Harris MI. Frequency and determinants of diabetes patient education among adults in the US population. Diabetes Care $1994 ; 17: 852-58$.

8. Gilden JL. Hendryx M. Casia C. Singh SP. The eflectiveness of diabetes education programs for older patients and their spouses. J Am Geriatr Soc 1989;37:1023-30.

9. Glasgow RE, Toohert DJ. Hampson SE, Brown JE, Lewinsolun PM, Donnelly J. Improving self-care among older pattients with type II diabetes: the sixty . . something study. Pattent Educ Couns 1992;19:61-74.

10. Wilson W. Pratt $C$. The impact of diabetes education and pecr support upon weight and glycemic control of elderly persons with non-insulindependent diabetes mellitus (NIDDM). Am J Public Health 1987:77:6.34-35.

11. Kronsbein P. Jurgens V. Muhlhauser I. Scholy V. Venhaus A. Berger M. Evaluation of a sriclured treatment programme on non-insulin-dependent diabeter. Lancet 1988:17(8625):1407-11.

12. Glasgow RE. Fakin EG. Toobert DJ. How generali/able are the results of diabetes self-mannagement research'? The impact of participation and attrition. Diabetes: Educ 1996:22(6):573-85.

13. Halter J. Anderson L. Herman W. et al. Intensive treatment salfely improves glycemic control of clderly pationts with diabetes mellitus. Diabetes 1993:+2(suppl 1): 1+6A.

14. Halter JB, Christensen NJ. Introduction: diabetes mellitus in elderly people. Diahetes Care 1990:13(suppl 2):1-2.

15. Morrow LA. Halter JB. Treatment of the elderly with diabetes. In: Kathn CR. Weir GS. eds. Joslin's diabetes mellitus. I3th ed. Philadelphia: Lea \& Fehiger, 1994:552-59.

16. Anderson LA, Fogler J, Dedrich RF. Recruiting from the community: lessoms learned from the Diabetes Care for Older Adults Project. Gerontologist 1995:35:395-401.

17. Funnell MM. Arnold MS, Barr PA. ed. Non-insulin-dependent diabeles mellitus: a curriculum for patients and health professionals. Ann Arbor. Mich: University of Michigan, Diabetes Research and Training Center, 1993.

18. Gilden JL. Hendryx MS. Clar S, Casia C. Singh SP. Diabetes support groups improve health are of older diahetic patients. J Am Geriatr Soc 1992:+10:1+7-50

19. A Diabetes Knowledge Test, form AC. Ann Arbor. Mich: Michigan Diabetes Research and Training Center. 1988.

20. Glasgow RE. Toohert DJ. Hampson SE. Participation in outpatient diabetes education programs: how many patients take part and how representative are they? Diabetes Educ 1991:17151:376-80. 